\title{
Avaliação de desempenho organizacional e sua importância para os centros acadêmicos de Secretariado Executivo
}

\section{Evaluation of organizational performance and its importance for academic centers of the Executive Secretariat}

\author{
Fábio Henrique Santos Ferreira ${ }^{1(\mathbb{D})}$, Natielle Maria Pontes do Nascimento ${ }^{2}$ (D) Kátia Regina Gonçalves \\ de Deus ${ }^{3}$ (D) Joseilme Fernandes Gouveia ${ }^{4}$ (D) \\ ${ }^{1}$ Universidade Federal da Paraíba (UFPB), Brasil, graduando em Secretariado Executivo Bilíngue (UFPB), e-mail: \\ fabio18henriquepe@gmail.com \\ ${ }^{2}$ Universidade Federal da Paraíba (UFPB), Brasil, graduada em Secretariado Executivo Bilíngue (UFPB), e-mail: \\ natielleaviao@gmail.com \\ ${ }^{3}$ Universidade Federal da Paraíba (UFPB), Brasil, Mestra em Linguística (UFPB), e-mail: katiargd83@ gmail.com \\ ${ }^{4}$ Universidade Federal da Paraíba (UFPB), Brasil, Doutor em Biometria e Estatística Aplicada (UFRPE), professor adjunto do \\ Departamento de Ciências Exatas (UFPB), e-mail: joseilme@ dcx.ufpb.br
}

\section{RESUMO}

O presente trabalho teve como propósito apresentar a percepção da importância que a avaliação de equipes proporciona para os Centros Acadêmicos (CA), dando ênfase no entendimento desse grupo enquanto uma instituição. Nesse âmbito, considera-se que o Centro Acadêmico, enquanto organização de terceiro setor, tem como finalidade principal buscar organizar atividades acadêmicas de integração entre os alunos do curso e Stakeholders, visando o seu desenvolvimento; e, por isso, necessita de mecanismos de avaliação e monitoramento para atingir suas metas. Com base nisso, o presente trabalho teve como objetivo geral contribuir com ferramentas de avaliação de desempenho que permita ações relevantes para os processos dos Centros Acadêmicos dos cursos de Secretariado Executivo. Especificamente, buscou-se: (1) verificar se os CAs de Secretariado avaliam o desempenho das equipes através de indicadores; (2) identificar quais indicadores tem sido utilizado no processo de avaliação; e, (3) observar a percepção dos membros dos CAs quanto às contribuições da avaliação de desempenho para os Centros Acadêmicos. A metodologia utilizada caracteriza-se como sendo de natureza bibliográfica, de cunho qualitativo e quantitativo. Como ferramenta de coleta de dados utilizou-se um questionário, o qual foi aplicado aos membros que se predispuseram a responder dos Centros Acadêmicos dos cursos de Secretariado dos estados de Pernambuco, Paraíba, Ceará, Minas Gerais e Pará. Os resultados mostraram que a avaliação de desempenho de equipes é um processo de grande importância nas devidas instituições, visto que, estas funcionam com o propósito de acompanhar e ao mesmo tempo mensurar as atividades que estão sendo desenvolvidas, a fim de proporcionar o crescimento e melhoria das equipes.

Palavras-chave: Secretariado Executivo. Centro acadêmico. Avaliação de desempenho.

\begin{abstract}
The purpose of this work was to present the perception of the importance that team assessment provides for Academic Centers, emphasizing the understanding of this group as an institution. In this context, it is considered that the Academic Center, as a third sector organization, has the main purpose of seeking organize academic integration activities between students of the course and Stakeholders, aiming at their development; and, therefore, it needs mechanisms to achieve its goals. Based on this, the present work had as general objective to contribute with performance evaluation tools that allow relevant actions for the processes of the Academic Centers of the Executive Secretariat courses. Specifically, we sought to: (1) verify whether the Secretariat ACs evaluate the teams' performance through indicators; (2) identify which indicators have been used in the evaluation process; and, (3) verify if the performance evaluation of the teams has contributed to the results of the Academic Centers. The methodology used is characterized bibliographic and exploratory nature, of a qualitative research. As a data collection instrument, a questionnaire was used, which was applied to the members of the Academic Centers of the Secretariat courses in the states of Pernambuco, Paraíba, Ceará, Minas Gerais and Pará. The results showed that the performance evaluation of teams is a process of great importance in the appropriate institutions, since it works with the purpose of monitoring and at the same time measuring the activities that are being developed, in order to provide growth and improvement of teams.
\end{abstract}

Keywords: Executive Secretariat. Academic center. Performance evaluation.

Revista Expectativa, Toledo/PR, v.20, n. 3, p. 46-70, jul./set., 2021. 


\section{INTRODUÇÃO}

O curso de Secretariado Executivo forma inúmeros profissionais no Brasil, por meio dos cursos técnicos e de bacharelado ofertados por instituições públicas e privadas, através da educação presencial ou à distância. O profissional de Secretariado tem a grande responsabilidade de assessorar pequenas, médias e grandes empresas, empreendedores e organizações sociais (NONATO JUNIOR, 2009).

Quando esse profissional parte para uma visão mais empresarial, ele passa a assessorar a gestão de empresas através da execução de ações que contribuem com o bom desempenho organizacional, favorecendo o ambiente de mudanças necessárias e exigidas pelo contexto interno e externo das organizações (BISCOLI; CIELO, 2004).

As organizações são instrumentos de estudos para os campos de diversas áreas do conhecimento, por isso detêm de abordagens amplas e complexas. Maximiano (2011) afirma que uma organização é um sistema de recursos (humanos e materiais), no qual os indivíduos envolvidos buscam alcançar um objetivo em comum, produtos ou serviços. Em síntese, as organizações empresariais necessitam de uma gestão organizacional que trabalhe de forma ampla e integrada, em função de mobilizar a equipe de trabalho para o alcance das metas (SCHULTZ, 2016).

As organizações são divididas em primeiro, segundo e terceiro setor. As organizações do terceiro setor (sem fins lucrativos), são entidades da Sociedade Civil, que aplicam seus excedentes na consecução de seu objetivo social (STAROSKY, 2020). Conforme aponta Starosky (2020), o marco regulatório das organizações do terceiro setor se deu pela aprovação da Lei 13.2014/2015, sendo criado então, um regime jurídico próprio.

Do ponto de vista formal e burocrático, e ainda pela finalidade de suas ações, os Diretórios/Centros Acadêmicos (CAs) são organizações do terceiro setor e possuem processos administrativos burocráticos, sendo constituídos por equipes que atuam a fim de atingir metas e objetivos em comum, com vistas a causa social. Os Diretórios Acadêmicos (DAs) possuem uma estrutura horizontalizada, pois, conforme observou Starosky (2020), essas entidades são associações, e seus membros, geralmente, são eleitos por assembleia e trabalham em equipes e de forma voluntária.

Revista Expectativa, Toledo/PR, v.20, n. 3, p. 46-70, jul./set., 2021. 
Sendo uma organização burocratizada, constituída por equipes, os Centros Acadêmicos necessitam de uma gestão organizacional, exercida pelo líder (gestor), para gerenciar as atividades desenvolvidas (MARIN et al., 2011). Assim, avaliar a equipes por meio de indicadores é uma alternativa para potencializar os resultados, conforme assevera Morioka et al. (2017), pois um sistema de avaliação de desempenho auxilia a gestão nas tomadas de decisões, contribuindo para o crescimento do desempenho organizacional e melhorando o relacionamento com a equipe, bem como para com os Stakeholders, que as pessoas que possuem interesses na gestão.

A metodologia que guiou esta pesquisa caracteriza-se como sendo de natureza bibliográfica, de cunho qualitativo e quantitativo. Como instrumento de coleta de dados utilizou-se um questionário, elaborado na plataforma Google Forms, com o objetivo de reunir informações necessárias para alcançar os resultados da presente investigação a partir do estudo aprofundado do referencial teórico e de diversas discussões entre autores.

O presente estudo norteia-se pela seguinte indagação: Os Centros Acadêmicos dos cursos de Secretariado avaliam o desempenho de suas equipes? Desse modo, tornou-se necessário também analisar quais ferramentas são utilizadas na avaliação, bem como a importância dessa metodologia para essas organizações.

O estudo apresenta-se relevante, pois além de analisar como os Centros Acadêmicos do curso de Secretariado avaliam o desempenho das equipes, visto que tomar decisões baseadas em dados e indicadores é reduz significativamente a chance de erro na gestão; a pesquisa ainda corrobora com abordagens teóricas para os temas de gestão organizacional e organizações de terceiro setor.

Com isso, este trabalho teve como objetivo geral analisar a percepção da importância da avaliação de desempenho para os processos dos Centros Acadêmicos dos cursos de Secretariado Executivo. Especificamente, buscou-se: (1) verificar se esses CAs avaliam o desempenho das equipes através de indicadores; (2) em caso positivo, identificar quais indicadores tem sido utilizado no processo de avaliação; e (3) observar a percepção dos membros dos CAs quanto às contribuições da avaliação de desempenho para os Centros Acadêmicos. 
Está pesquisa foi motivada pela necessidade de compreender a realidade da qual os autores, participantes do estudo, fazem parte e, ainda, contribuir com ferramentas que possam posicionarem com ações relevantes os CAs dos cursos de Secretariado.

\section{REFERÊNCIAL TEÓRICO}

\subsection{HISTÓRICO DO CURSO DE SECRETARIADO NO BRASIL}

Analisando as atribuições do Secretário Executivo, conforme explica a Lei que regulamenta a profissão, Lei 7.377, de 30 setembro de 1985, a qual foi complementada posteriormente pela Lei 9.261, de 10 de janeiro de 1996, é possível identificar a aproximação desse profissional com os processos de assessoramento das esferas deliberativas da gestão, visto que, antes suas atribuições eram restritas apenas aos âmbitos mais operacionais, vinculados mais precisamente aos serviços de escritório (NONATO JÚNIOR, 2009).

O profissional de Secretariado Executivo, no Brasil, é formado através de cursos técnicos e de bacharelado, isso, em instituições públicas e privadas de ensino superior, podendo ser aplicado nas modalidades de educação presencial e também à distância (FENASSEC, 2008).

Desse modo, pode-se constatar que a evolução da profissão de secretariado pode ser atribuída, especialmente, à vasta grade curricular que os cursos de graduação vêm utilizando como base para aprimorar os conhecimentos dos futuros profissionais (NONATO JÚNIOR, 2009).

Diante disso, percebe-se que, as atribuições deste profissional nos dias atuais vêm se modificando ainda mais para atender as demandas existentes no contexto laboral e se tornando cada vez mais complexas, para além do que regulamenta a Lei 7.377; pois, o mercado de trabalho exige cada vez mais profissionais capacitados para o atual cenário organizacional. Com isso, o profissional de Secretariado vem buscando sempre, conforme ditam as novas tendências e inovações, uma melhor formação e aperfeiçoamento (NEIVA; D’ÉLIA, 2009).

\subsection{GESTÃO ORGANIZACIONAL}

Gestão organizacional é o planejamento, organização, direção, controle dos recursos de

Revista Expectativa, Toledo/PR, v.20, n. 3, p. 46-70, jul./set., 2021. 
todas as ações que busquem contribuir positivamente com resultados de determinada organização ou setor. A gestão busca conduzir pessoas e processos com eficiências e melhor contínua construindo ambiente colaborativo e favorável ao autodesenvolvimento e ao alcance de metas, objetivos e resultados em comum (DAFT, 2014).

Conforme salientaram Paglisou et al. (2010), organizações são "construções sociais", em que são importantes as instalações físicas, as relações interpessoais, a natureza humana e as relações externas. Ao passo que os indivíduos necessitam das organizações, estas dependem das pessoas, pois essa construção deve acontecer de forma cooperativa e integrada.

Nesse entendimento, Schultz (2016, p.20) afirma-se que as organizações são resultados do processo adaptativos à forças externas, centralizados e conduzidas por um líder em ambientes socioculturais e por ideologias.

A gestão organizacional consiste em uma abordagem mais ampla do que o da administração, por exemplo. Conforme afirmam Roman et al. (2017), administrar consiste em planejar, organizar, dirigir e controlar recursos, a fim de atingir um objetivo. Em contrapartida, a gestão organizacional constitui-se em um conjunto de práticas e atividades fundamentadas sobre princípios pré-estabelecidos, que visam a uma finalidade paralela a estudos constantes sobre os processos organizacionais (SCHULTZ, 2016).

\subsubsection{Equipes de trabalho}

À medida que o mercado vem se tornando mais competitivo, as empresas precisam de profissionais capacitados e que tenham facilidade e habilidades para trabalhar em equipe. Nesse entendimento Weber e Grisci (2010, p.1) afirma:

\footnotetext{
O trabalho especializado, executado individualmente, submetido à rígido controle hierárquico foi sendo substituído por um modo de trabalhar que passou a enfatizar o trabalho coordenado por meio de equipes, às quais se delega certo poder de decisão, o que visa melhorar e acelerar o processo de trabalho. Pouco a pouco, o modelo de trabalho em equipe foi ocupando lugar de destaque nas práticas organizacionais, veiculados por um discurso que passou a caracterizá-lo como pleno de qualidades, capaz de responder flexivelmente às exigências do mercado.
}

Ademais, em concordância com Katzenbach e Smith (1994, p. 75) relatam que: "O trabalho em equipe é formado por um grupo de pessoas em pequena quantidade, cujo 
conhecimento é complementado, os membros são comprometidos com as metas, e todos se mantêm conjuntamente responsáveis pela performance e alcance dos objetivos."

Em seu estudo, Weber e Grisci (2010) apontam que as equipes podem ser divididas e classificadas em: células de produção, equipes de alta performance, mini fábricas, alto desempenho, entre outras. As equipes passam a ser um vetor competitivo no que diz respeito à produtividade e à eficácias das ações, pois trabalhando em conjunto, produzem mais:

\begin{abstract}
As equipes têm outra clara vantagem[...], sobre os esforços isolados: o apoio mútuo que surge entre seus membros. O sinergismo que vem de pessoas trabalhando juntas de maneira produtiva em um projeto importante é em geral suficiente para o entusiasmo e apoio mesmo em tempos difíceis. Quando o espírito de equipe invade uma organização, todos os empregados começam a trabalhar juntos visando à qualidade - sem barreiras, sem facções, todos em uma única equipe, movendo-se juntos na mesma direção. (SOUSA; CAMPOS; RAMOS, 2001, p. 10, grifo nosso).
\end{abstract}

O desenvolvimento pessoal e de equipe é importantíssimo para toda organização, pois aumenta a vantagem competitiva e a interação do grupo, servindo como base de sustentação, uma vez que, o resultado coletivo é fundamental para toda organização (FRANCO; SANTOS, 2010).

Portanto, para trabalhar em equipe é pertinente o senso de missão compartilhada e responsabilidade coletiva, uma vez que a equipe precisa saber o motivo de sua consolidação e os objetivos que almejam alcançar, para atuar de maneira cooperativa (BRAGA; OLIVEIRA; SIENA, 2011). Além disso, para que o trabalho em equipe aconteça com êxito, é necessário que os indivíduos envolvidos se sintam parte integrante no processo, pois conforme observou Vergara (2009, p. 38) "nesse contexto, trabalhar em equipe requer, de cada um, sentir-se, realmente, como membro pertencente. Sem esse sentimento, dificilmente um conjunto de pessoas se tornará uma equipe".

\title{
2.1.2 Avaliação de desempenho das equipes
}

À medida que o processo de globalização atrelado aos avanços tecnológicos vem progredindo, as empresas precisam adotar e implementar medidas estratégicas para sobreviver no mercado altamente competitivo, medidas essas que envolvem a avaliação do capital humano. A priori, avaliar a equipe é observar o andamento dos processos, então, conforme salientam

Revista Expectativa, Toledo/PR, v.20, n. 3, p. 46-70, jul./set., 2021. 
Guimarães, Nader e Ramagem (1998, p. 44), “a avaliação do desempenho de pessoal deve ser entendida como um processo, que se inicia com um planejamento e termina com a comparação entre o executado e o planejado".

As empresas passaram a adotar a avaliação de desempenho de grupos e equipes, ou até mesmo de forma individual, a fim de avaliar as atividades realizadas pelos colaboradores, através de indicadores de desempenho. Mitchell (2004 apud MUNARETTO; CORRÊA, 2016), evidencia que indicador é uma ferramenta que permite o alcance de informações de uma realidade analisada, informações essas que devem ser estreitadas com a finalidade de reter apenas o conteúdo essencial para a empresa.

Morioka et al. (2017) explicam que os indicadores de desempenho organizacional são métricas altamente importantes a serem utilizadas pelos gestores, além disso, esse sistema pode ser aplicado como base para a tomada de decisão, pois quantifica a eficiência e eficácia das ações desenvolvidas pelas equipes de trabalho.

Paralelamente, Vargas et al. (2016) aduzem que os indicadores de desempenho ou KPIs, da sigla em inglês Key Performance Indicator, são classificados em indicadores financeiros e não-financeiros. Munaretto e Corrêa (2016), Vargas et al. (2016) e Marioka et al. (2017) apontam que o mais eficiente, em relação à amplitude da investigação seria o indicador nãofinanceiro, pois a vantagem deste deve-se ao fato de operar como mecanismo de controle ou de incentivo, auxiliam no processo de entendimento da cultura organizacional e interagem de forma integrada com a hierarquia, além de reduzir conflito; enquanto os financeiros são resultados de ações já executadas.

Ratificando esse entendimento, segundo Simons (2000 apud MUNARETTO; CORRÊA, 2016, p. 28) os indicadores podem ser utilizados ainda para os seguintes propósitos gerenciais:

- Controle: Utilizar dos feedbacks para construir processos de melhorias de acordo com as metas organizacionais;

- Sinais: Comportamentos e atitudes comunicadas com clareza pelos gerentes definindo preferências, valores e oportunidade desejadas pela organização;

- Educação e aprendizado: Com as constantes mudanças nos ambientes interno e externo é de fundamental importância capacitar todos membros com conhecimento

Revista Expectativa, Toledo/PR, v.20, n. 3, p. 46-70, jul./set., 2021. 
atualizado;

- Comunicação externa: Utilizar meios e recursos que estabeleçam uma comunicação clara e objetiva alinhados a indicadores de desempenho e lucratividade são essenciais para qualquer negócio.

Conforme observado na literatura, a avaliação de desempenho é dividida em várias partes, na qual cada tipo de avaliação possui uma configuração distinta. De acordo com (MORAES; BERNARDINI, 2016), as mais abordadas ultimamente pelas organizações são: avaliação por superior imediato (a forma mais tradicional, quando o colaborador é avaliado pelo gestor direto), avaliação direta ou 90 graus (o líder avalia o colaborador com a ajuda de outro setor), avaliação conjunta ou 180 graus (o líder e o avaliado conversam entre si), avaliação 360 graus (todos os envolvidos no processo participam da avaliação, colaboradores, clientes). A avaliação de desempenho pode ser realizada através de questionários em formato online, entrevistas presenciais e também por meio de relatórios gerenciais, conforme aponta pesquisa desenvolvida por Aranha, Leichsenring e Folegatti (2015).

Em suma, uma empresa que adota a avaliação de desempenho emerge para um avanço integrado e contínuo, atrelado aos objetivos e metas estabelecidas, além de fornecer aos gestores informações as quais auxiliam nas tomadas de decisões futuras.

\subsection{CENTRO ACADÊMICO - UMA ORGANIZAÇÃO DO TERCEIRO SETOR}

Os Centros Acadêmicos são associações e/ou entidades sem fins lucrativos, no Brasil foi regulamentado 31 de outubro de 1985 pela lei federal $n^{\circ}$ 7.395. Nos CAs podem ser desenvolvidas diversas atividades, tais como: discussões, atividades acadêmicas e culturais, ações políticas dos estudantes, semana temáticas, visitas técnicas em empresas privadas e órgão públicos, mediações e negociações em geral.

As organizações são divididas em primeiro setor (governo), segundo setor (empresas privadas) e terceiro setor (organizações sem fins lucrativos). Desse modo, em função dos objetivos desse trabalho, será contextualizada apenas a organização do terceiro setor (MARIN, 2011).

Essas organizações estão presentes em diversos países, conforme apontaram Guimarães,

Revista Expectativa, Toledo/PR, v.20, n. 3, p. 46-70, jul./set., 2021. 
Pinho e Leal (2010), diversos grupos da sociedade vêm se reunindo com propósitos voltados para o âmbito social. No entanto, de acordo com França (2007, p. 14), “a partir da década de 90, o denominado Terceiro Setor entrou em evidência no Brasil, o que trouxe como consequência, entre outros, o aumento do número de entidades sem fins lucrativos".

É sabido que essas organizações existem na sociedade há décadas, antes mesmo de receber a nomenclatura de "terceiro setor", através das ações de caridade promovidas por instituições religiosas e hospitalares. Paralelamente, sobre o marco regulatório, conforme descrito por Starosky (2020, p. 22):

\begin{abstract}
A Lei 13.2014/2015, conhecida como o "Marco Regulatório do Terceiro Setor, ou das Organizações da Sociedade Civil (MROSC)", nasceu a partir da percepção de que era necessário desenvolver uma regra moderna, que disciplinasse as relações entre Poder Público e as OSCs, sob uma perspectiva gerencialista, de controle por resultados, nas parcerias mútuas por cooperação. O principal avanço foi a criação de um regime jurídico próprio para estas parcerias.
\end{abstract}

O autor expõe ainda que a Lei estabelece um conceito para Organização de Sociedade Civil, em razão de existir uma confusão em relação ao conceito, então, segundo salientaram Koyama (2015) e Renzetti (2017, apud STAROSKY, 2020, p. 24), "são consideradas OSC as entidades privadas sem fins lucrativos, que aplicam seus excedentes na consecução de seu objeto social, as cooperativas de trabalho e as organizações religiosas que se dediquem à atividades ou projetos de cunho social.

Paralelamente, a Lei 7.395, assegura em seu art. $4^{\circ}$ para os estudantes que estejam no nível superior, o direito à organização de Centro/Diretórios Acadêmicos. Ainda no art. $5^{\circ}$ explica-se que o funcionamento, a organização e as atividades destas entidades CAs ou DAs devem obedecer à Lei de seus estatutos que são aprovados, em assembleia-geral ou através de congressos nas demais entidades (BRASIL, 1985).

Dessa perspectiva, os CAs podem ser considerados organizações, pois são compostos por uma equipe de pessoas do mesmo curso, que buscam atender as necessidades dos alunos perante a coordenação do curso e outros públicos/entidades. Essa perspectiva corrobora com a colocação de Starosky (2020), pois o escritor explica que as organizações horizontalizadas possuem processos administrativos, definição da autoridade no papel do líder da equipe (determinado por assembleia), e ainda a transparência dos processos organizacionais, por meio

Revista Expectativa, Toledo/PR, v.20, n. 3, p. 46-70, jul./set., 2021. 
de prestações de contas e relatórios.

O Centro Acadêmico pode, ainda, se configurar como uma organização do terceiro setor, e/ou horizontalizada, pois conforme analisou Starosky (2020), as organizações horizontalizada são cooperativas, uma vez que buscam reunir pessoas (voluntários), no qual as equipes são eleitas por meio de assembleias.

Os alunos escolhidos por todos os demais para compor o Centro Acadêmico, tem uma responsabilidade grandiosa frente aos discentes, pois, através deles é realizada uma grande demanda de solicitações, tendo em vista que esse espaço permite aos alunos gestores o contato com stakeholders, possibilitando também o engajamento interno e externo (MARIN, 2011). Marin et al. (2011) apontam ainda que essa entidade representativa desempenha funções variadas, percorrendo diversos âmbitos e atividades, dentre essas a organização de viagens técnicas e minicursos.

O Centro Acadêmico não atua somente nessas causas, embora sejam importantes, se preocupa com o que acontece no dia a dia do aluno. Com isso, promove eventos onde possa haver uma troca, com os demais alunos e até mesmo a com a comunidade local.

Para Fidelis (2016, p. 20), as funções de um Centro Acadêmico podem ser:

\footnotetext{
Suas funções podem ser, e em geral são, diversas. Algumas delas são: a organização de atividades acadêmicas extracurriculares como debates, discussões, palestras, semanas temáticas, recepção de calouros e realização de projetos de extensão; encaminhamento, mobilização e organização de reivindicações e ações políticas dos estudantes; mediação de negociações e conflitos individuais e coletivos entre estudantes e a universidade; realização de atividades culturais como feiras de livros, festivais diversos, entre outros.
}

Sendo assim, é notória a importância da atuação de um Centro Acadêmico, que trabalhe de forma integrada por todos que dependem de sua voz para que outras vozes sejam ouvidas e atendidas no campo de atuação, no que diz respeito a assistência dos estudantes, e algumas vezes, até a nível nacional, assistindo tanto o público interno quanto o externo.

\section{PROCEDIMENTOS METODOLÓGICOS}

A presente pesquisa é do tipo bibliográfica, com abordagem qualitativa e quantitativa. A pesquisa bibliográfica designa-se a produção textual através de materiais que já foram 
publicados, a exemplo de livros, jornais, anais de eventos científicos, revistas, e outros, diante disso, Gil (2010) explica ainda que quase todas as pesquisas podem ser consideradas bibliográficas, uma vez que existe a necessidade de realizar uma fundamentação teórica do trabalho e a identificação dos avanços científicos de determinada área de conhecimento.

Desta forma, a pesquisa foi baseada em abordagens que relacionam as temáticas sobre a gestão organizacional, a avaliação de desempenho de equipes, elencando de forma prioritária o centro acadêmico como uma organização de terceiro setor.

$\mathrm{Na}$ visão de Creswell (2010), a pesquisa qualitativa busca responder a questões particulares, se preocupando com as ciências sociais, em uma realidade que não pode ser quantificada. Esta pesquisa trabalha com um universo de significados, valores, atitudes e crenças, correspondendo a um espaço mais profundo das relações.

O público-alvo escolhido para responder a esta pesquisa foram estudantes dos cursos de Secretariado Executivo que atuam em Centro/Diretório Acadêmico do Brasil.

Como instrumento de coleta de dados utilizou-se um questionário, elaborado na plataforma Google Forms, que foi aplicado no período de 15 a 24 de julho de 2020, através do WhatsApp e também por E-mail. O questionário continha 21 (vinte e uma) questões e foi aplicado com 16 (dezesseis) membros dos Centros Acadêmicos de Secretariado.

Vale destacar que se contatou, de um total de 25 (vinte e cinco) cursos superiores de Secretariado, existentes no Brasil, um quantitativo de 12 (doze) CAs ativos, para os quais foram encaminhados o questionário de pesquisa. No entanto, obteve-se um retorno de 16 (dezesseis) respondentes de cinco estados, sendo 3 da Universidade Federal Paraíba, 4 da Universidade Federal de Viçosa, 4 da Universidade Federal do Ceará, 2 de Universidade Federal de Pernambuco e 3 da Universidade Federal do Pará.

Na técnica de análise dos dados, utilizou os softwares Microsoft Word, Microsoft Excel e Statistical Package for the Social Sciences (SPSS). O Word serviu de suporte para a categorizar as respostas qualitativas e o Excel auxiliou na construção dos gráficos, já o SPSS foi utilizado para compreensão dos dados quantitativos, os quais serviram de base para uma análise descritiva. O SPSS é um software de análise estatísticas avançadas muito utilizado na área de ciências sociais (MARÔCO, 2018). 


\section{APRESENTAÇÃO E ANÁLISE DOS RESULTADOS}

Esta seção se propõe a apresentar os resultados obtidos nas análises, por meio da interpretação dos dados adquiridos através dos questionários aplicados com os membros dos Centros Acadêmicos dos cursos de Secretariado.

Inicialmente, buscou-se compreender qual a concepção dos membros dos CAs sobre o Centro/Diretório Acadêmico enquanto uma organização burocratizada, conforme expõe o Gráfico 1. Percebeu-se que 40\% dos respondentes afirmam não saber, 33,3\% entendem que os CAs se caracterizam como uma instituição do terceiro setor e $20 \%$ responderam ser do primeiro setor.

Gráfico 1 - Âmbito do CA enquanto uma organização

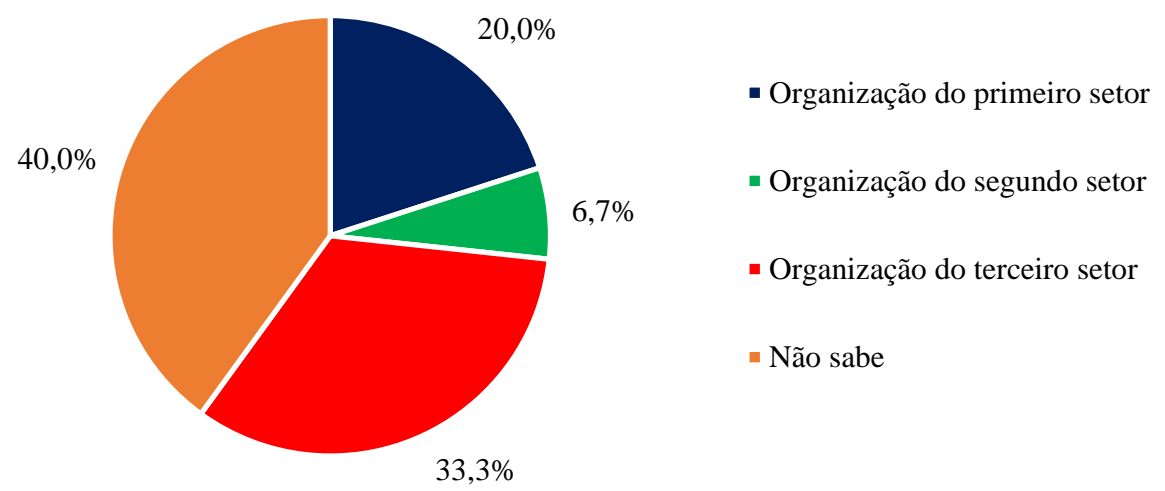

Fonte: Dados da Pesquisa (2020)

A análise do gráfico acima possibilita compreender que a maioria dos respondentes, ou seja 67\% destes, não sabem ou erraram em qual setor se inclui o Centro Acadêmico enquanto uma organização. Os Centros Acadêmicos são considerados como organizações do terceiro setor, pois esses grupos são constituídos por indivíduos que trabalham em uma causa de cunho social, de forma voluntária (GUIMARÃES; PINHO; LEAL, 2010). É necessário que os membros dos CAs tenham esse conhecimento para compreender de forma integrada, nas esferas administrativas, como essas entidades funcionam.

Quando questionados sobre o que os alunos esperam que seja realizado por seu Centro Acadêmico nos próximos anos, os respondentes, de modo geral, desejam que os respectivos

Revista Expectativa, Toledo/PR, v.20, n. 3, p. 46-70, jul./set., 2021. 
CA promovam ações de incentivo às atividades acadêmicas, proporcionando assim também, maiores experiências e representatividade do curso.

Quadro 1 - O que os alunos esperam que seja realizado pelo Centro Acadêmico.

Ações de incentivo às atividades acadêmicas.

Buscar parcerias, ampliar a divulgação do curso e a profissão em empresas.

Ações que integrem todos os cursos que fazem parte dele. Por meio de uma experiência, percebi que muitos alunos de outros cursos não sabem, sequer, da existência do Curso de Secretariado Executivo.

Fonte: Dados da pesquisa, 2020.

Através do Quadro 1 é possível perceber que será necessária uma divulgação maior, propagando o curso na esfera estudantil e profissional, pois, em alguns estados ainda se encontra dificuldade na amplitude desta divulgação.

Ao serem indagados sobre qual o principal meio de comunicação que o seu CA utiliza para dialogar com a comunidade acadêmica, 93,8\% dos participantes responderam que atuam nas Redes Sociais, que se subdividem em duas principais ferramentas: WhatsApp e Instagram, os outros 6,2\% atuam através de e-mails, que também é uma ferramenta de grande importância na comunicação.

O WhatsApp é um aplicativo gratuito que existe para a troca de mensagens que está disponível para celular, tablet, computador, entre outras plataformas digitais; este aplicativo possibilita o envio de mensagens digitadas e de voz, assim como o envio de arquivos, ligação de voz ou vídeo (CARVALHO, 2015).

Desta forma, este é o principal meio que os Centros Acadêmicos utilizam na comunicação com toda a comunidade acadêmica, assim como com os professores e a coordenação, por meio dos grupos e por conversa individual.

De acordo com a empresa Rock Content (2018), a rede social Instagram é uma das ferramentas de maior utilização nos dias atuais, que, permite uma maior facilidade na interação e comunicação entre as pessoas que utilizam a mesma rede social, além de ter um grande potencial de investimento.

Diante disso, compreende-se que o Instagram para esses Centros Acadêmicos tem promovido um grande engajamento no que diz respeito à comunicação e divulgação de

Revista Expectativa, Toledo/PR, v.20, n. 3, p. 46-70, jul./set., 2021. 
propostas e resultados, para que seja possível, assim como o WhatsApp, chegar a todo o públicoalvo que necessita receber as informações necessárias.

Dando continuidade, os participantes foram questionados se concordam ou discordam à respeito da realização de avaliação de desempenho nos CAs, e se os membros dos CAs recebem feedbacks dessas avaliações, conforme destacado no Gráfico 2.

Gráfico 2 - Feedbacks das avaliações

$80 \%$

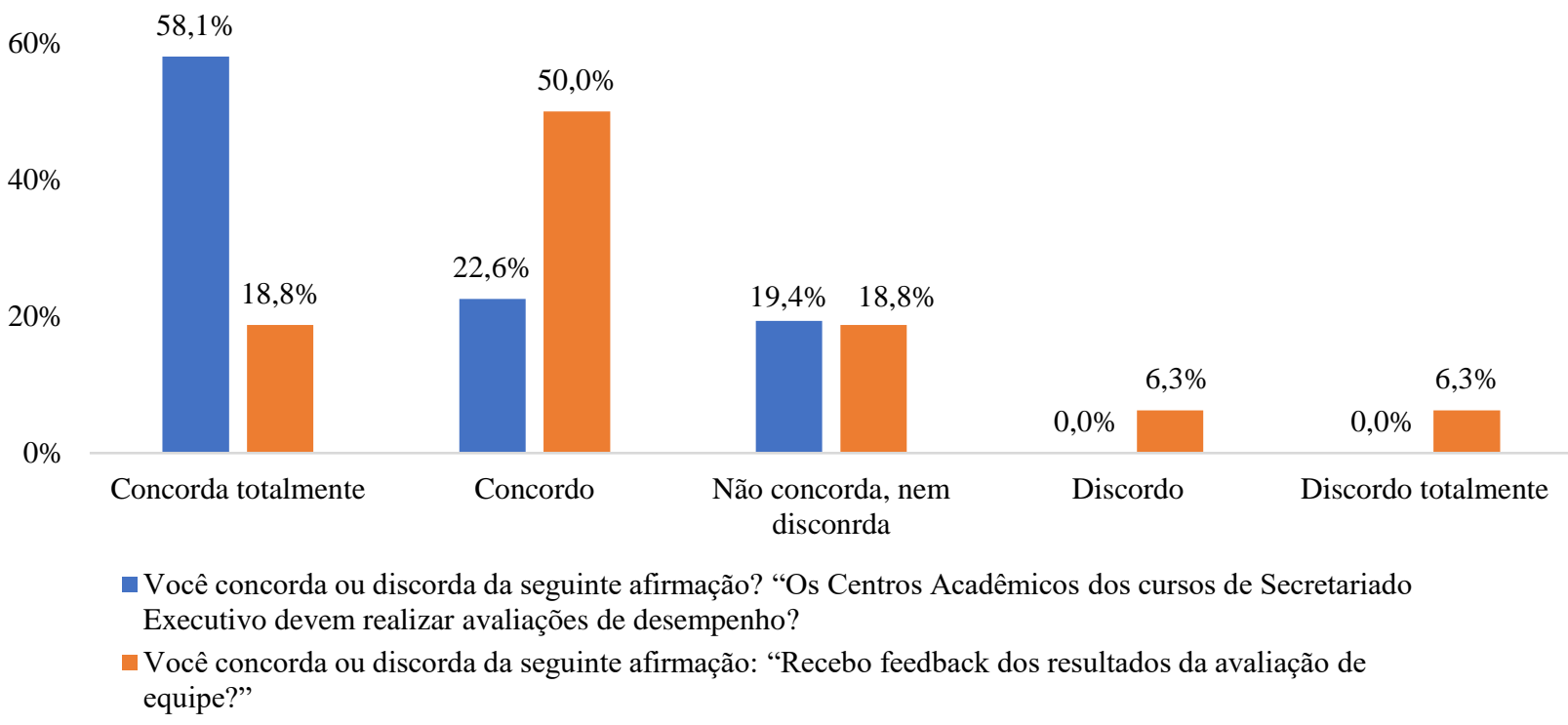

Fonte: Dados da Pesquisa (2020)

É possível observar através do Gráfico 2, que a maior parte dos respondentes concordam totalmente com a primeira afirmação, que diz respeito aos Centros Acadêmicos realizarem as avaliações de desempenho de equipes. E, apesar da maioria não ter implementado essa metodologia, podendo ser observado no Gráfico 4, percebem a importância deste procedimento. Conforme observado no estudo de Guimarães, Nader e Ramagem (1998), o feedback é de suma relevância nesse processo. Então, em relação ao feedback sobre os resultados da avaliação de equipes, nota-se que nem todos têm a oportunidade de receber este retorno, o que torna esse processo ineficaz, porém, em grande parte, há concordância. 
No Gráfico 3, a seguir, foi questionado se o grupo atua de forma sinérgica ou individualizada. Em forma significativa, $80 \%$ afirmaram que o trabalho é sinérgico, e $20 \%$ afirmam trabalhar de forma individualizada.

Gráfico 3 - Forma que a equipe trabalha

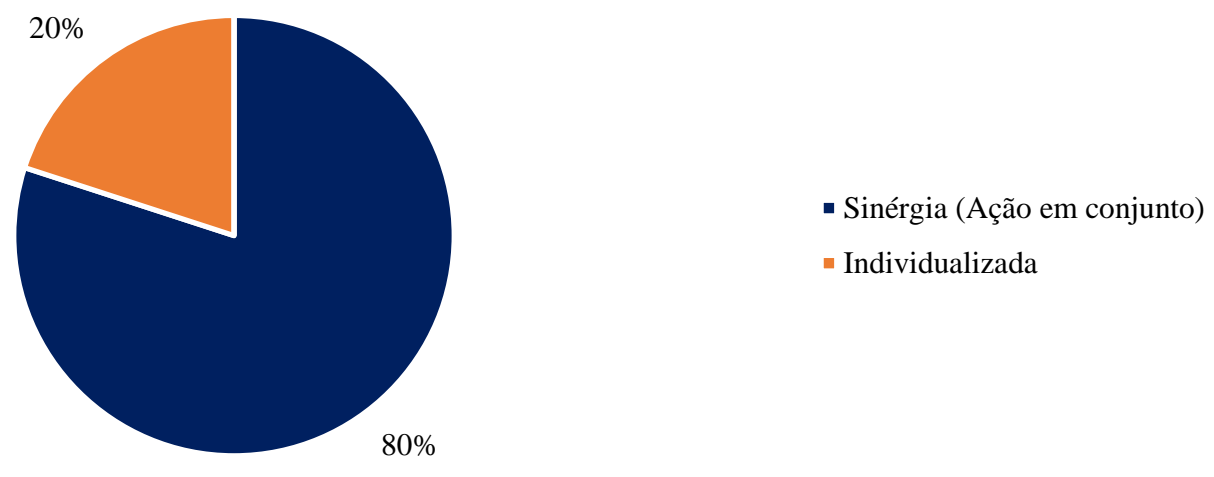

Fonte: Dados da Pesquisa (2020).

Para que ocorra o trabalho sinérgico, é necessário que o senso de missão compartilhada e o de responsabilidade coletiva sejam objetivados de forma clara, para que haja estimulação do alcance das metas e estímulo do trabalho cooperativo (BRAGA; OLIVEIRA; SIENA, 2011). O trabalho sinérgico possibilita uma maior interação entre os membros e maior comprometimento com as atividades. Nessa perspectiva, a realização de reuniões e encontro das equipes, colaboram para que ocorra uma maior interação entre os membros.

Em relação à frequência com que o Centro Acadêmico realiza o processo de avaliação de desempenho de equipe, demonstrado no Gráfico 4, analisou-se que, apesar de verificar que muitos Centros Acadêmicos realizam a avaliação de desempenho de equipe (totalizando 66,7\% das respostas), na sua maioria por meio de reuniões semanais ou mensais e no dia a dia; existe também uma parte significativa que não realiza a avaliação de suas equipes (destacada por $26,7 \%$ dos participantes). Como a gestão do CA, geralmente tem validade de um ano, pode-se avaliar semanal, mensal ou até semestralmente, dependendo da necessidade de cada organização. 
Gráfico 4 - Frequência das avaliações

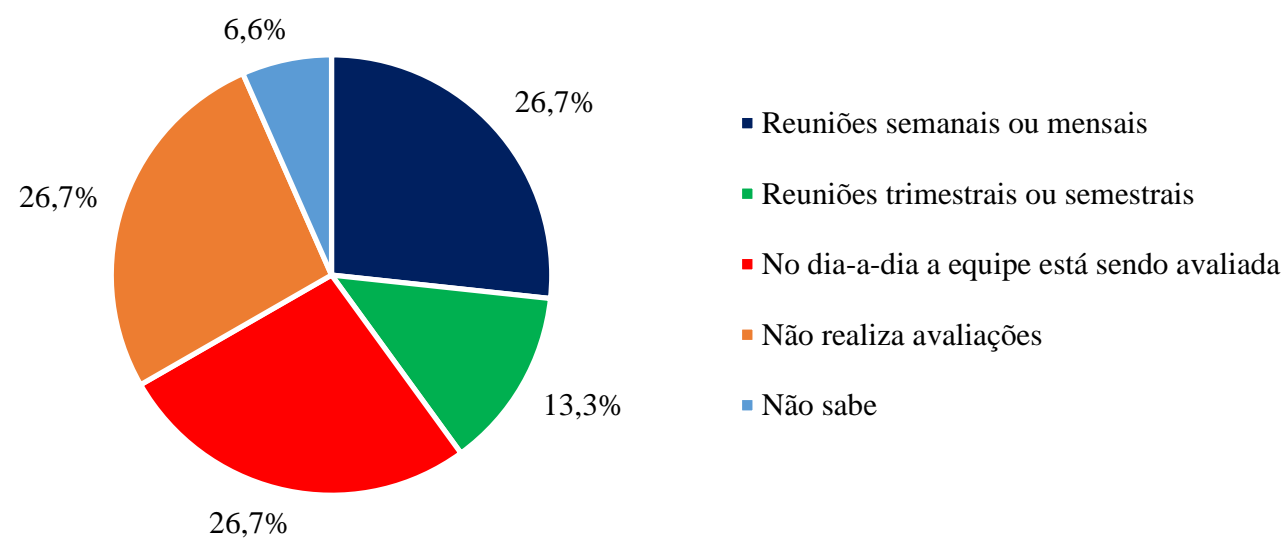

Fonte: Dados da Pesquisa (2020)

É importante a compreensão de que esta avaliação é necessária no processo de colaborar para o próprio desempenho da equipe, que, ao compreender onde precisa melhorar, engrandece o Centro Acadêmico, ao mesmo tempo em que corrobora com a expansão do curso, através do melhoramento do próprio CA.

Dentre os que realizam avaliações é possível observar no Gráfico 5 que 63,3\% afirmam ser por meio de reuniões, $27,3 \%$ relataram não saber, e $9,1 \%$ dizem ser por meio de relatório gerencial.

Gráfico 5 - Processos nos quais ocorrem as avaliações

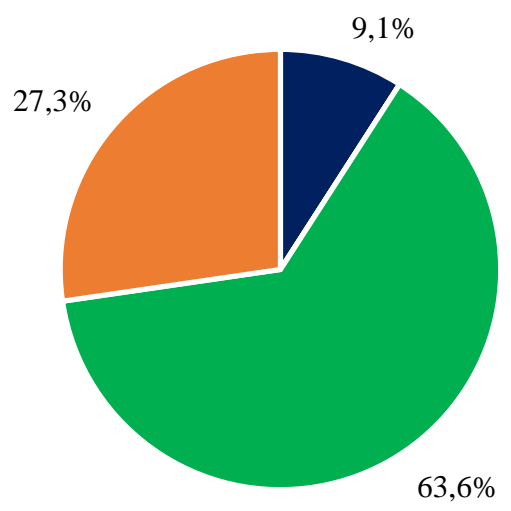

- Relatório gerenciais

- Reuniões

- Não sabe

Fonte: Dados da Pesquisa (2020).

Existem diversos métodos que podem ser utilizados pelos CAs para realizar as avaliações das equipes, dentre estes, destaca-se as reuniões (informal) e os relatórios gerenciais 
(formal). No entanto, a necessidade de formalização vai depender da estrutura da organização (GUIMARÃES; NADER; RAMAGEM, 1998). Então, para que haja uma maior clareza e eficácia nesse processo, é mais adequado que ocorram através de questionários e relatórios gerenciais, sem pré-julgamentos, pois estes permitem um diagnóstico preciso do que foi avaliado, e do resultado no geral.

Em relação a como os respondentes avaliam, de modo geral, o desempenho dos integrantes do CA de sua instituição, foi feita a seguinte análise, conforme aponta o gráfico 6.

Gráfico 6 - Nível de desempenho

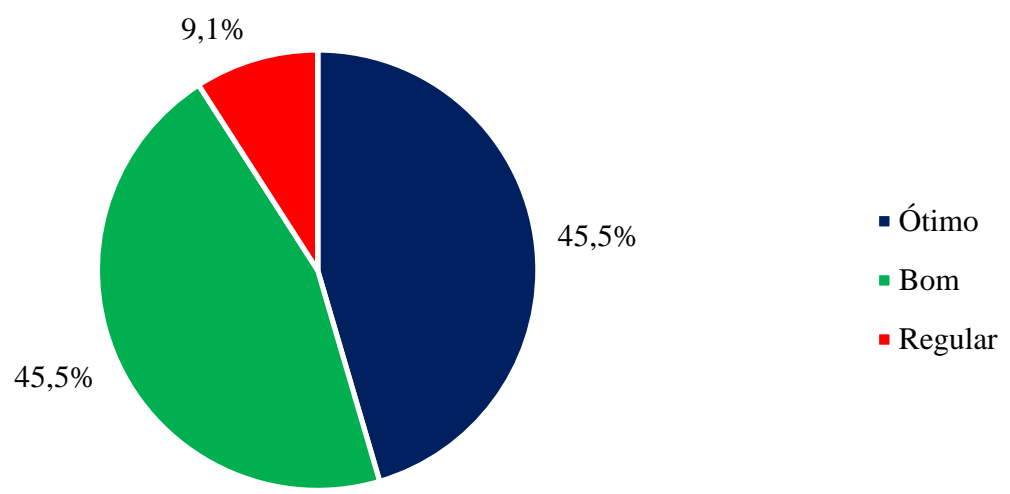

Fonte: Dados da Pesquisa (2020).

É muito importante destacar a relevância das equipes realizarem esta avaliação, em relação ao desempenho em conjunto. Portanto, os dados revelam que a maioria acredita que existe sim um bom desempenho dos CAs (totalizando 91\% das respostas). No entanto, vale destacar que existem também grupos que não estão completamente satisfeitos (um total de $9,1 \%)$, os quais acreditam que os membros possuem um desempenho regular. 
Gráfico 7 - Indicadores utilizados

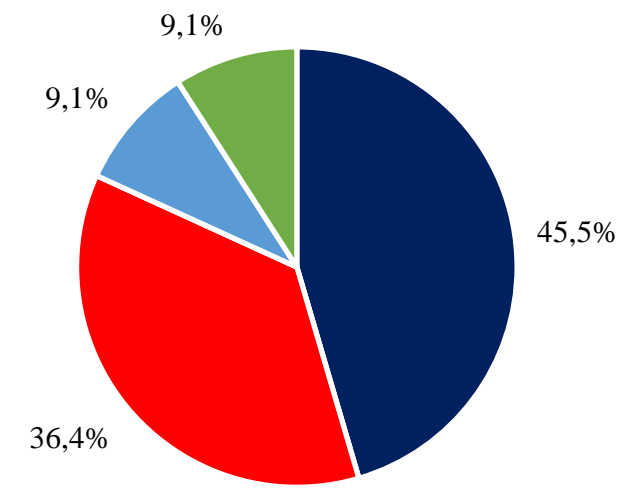

- De produtividade

- De qualidade

- Produtividade, qualidade e resultados

- Não sabe

Fonte: Dados da Pesquisa (2020).

No gráfico 7, foi analisado qual o indicador mais utilizado pelas equipes para avaliar o desempenho CA. Percebe-se que a maior parte dos respondentes, ou seja, (45,5\%), afirmam que o indicador utilizado baseia-se na métrica de produtividade; enquanto 36,4\% afirmam medir a qualidade. Esses indicadores são de suma importância para o desempenho dos CAs, pois quantificam a eficiência e eficácia, permitindo à gestão e aos demais membros, destrinchar e observar os resultados dos objetivos e metas pré-estabelecidos (MARIOKA et al., 2017). Paralelamente, os indicadores utilizados pelos Centros Acadêmicos são aqueles que não avaliam os aspectos financeiros, pois estes possuem um objetivo mais amplo, possibilitando o controle ou até mesmo incentivo, além de auxiliar no processo de entendimento da cultura organizacional.

Considerando os tipos de desempenho de avaliação mais abordados pela literatura e exposto no referencial teórico, perguntou-se aos participantes sobre qual o tipo de avaliação desempenho o seu CA utiliza. Desse modo, verifica-se as respostas no Gráfico 8. 
Gráfico 8 - Tipos de avaliação de desempenho.

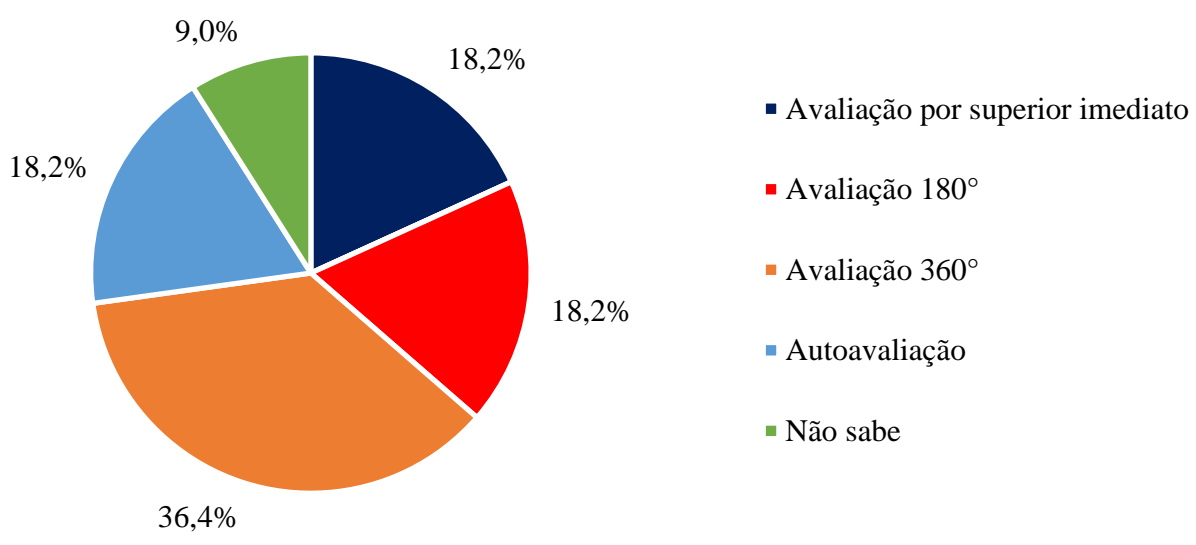

Fonte: Dados da Pesquisa (2020)

Em conformidade com os dados, observa-se que a maior parte, composta por $36,4 \%$ dos respondentes, afirma que a avaliação 360 graus é a mais utilizada. Por meio desta, todos os envolvidos no processo participam da avaliação, dentre eles os colaboradores e estudantes. É possível constatar também que os demais respondentes afirmam realizar as avaliações 180 graus, autoavaliação e avaliação por superior imediato, constituindo 18,2\% dos respondentes, respectivamente, o que demonstra um leque de possibilidades em relação ao formato de avaliação que essas organizações podem realizar.

Em relação à avaliação de equipes, com o propósito de saber com qual finalidade esta é realizada, foi feita a análise disponibilizada no Gráfico 9. A maioria dos respondentes $(63,6 \%)$ compreendem que a avaliação realizada com as equipes tem como principal fator construir um processo de melhoria contínua para o próprio grupo, expandindo para todo o curso, e também, com a pretensão de saber quem está desempenhando bem as suas atividades no Centro Acadêmico, conforme exposto no referencial teórico 
Gráfico 9 - Com qual finalidade é realizada a avaliação de desempenho?

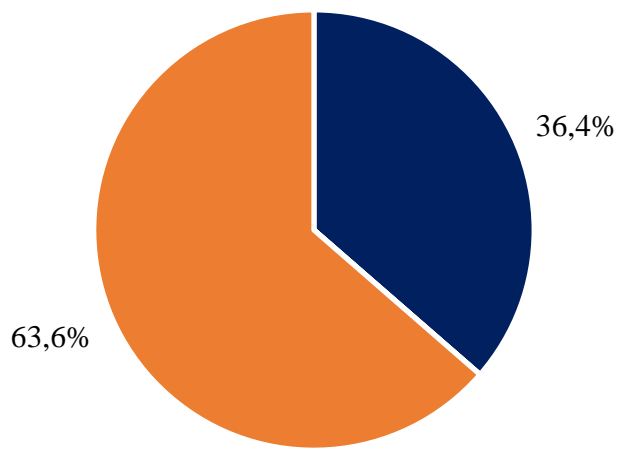

- Saber que está desempenhando bem as atividades

- Construir um processo de melhoria contínua

Fonte: Dados da Pesquisa (2020).

Dando sequência, questionou-se os participantes sobre como os resultados da avaliação de desempenho são apresentados e debatidos com os membros dos CAs. Sendo assim, pode-se observar as respostas no Gráfico 10. Com base nos dados apresentados, observa-se que 54,5\% dos participantes afirmam que os resultados das avaliações desempenho são repassados através de reuniões, 18,2\% expõem que acontece de forma individual, enquanto 18,2\% declaram que os resultados não são discutidos.

Gráfico 10 - Feedbacks dos resultados

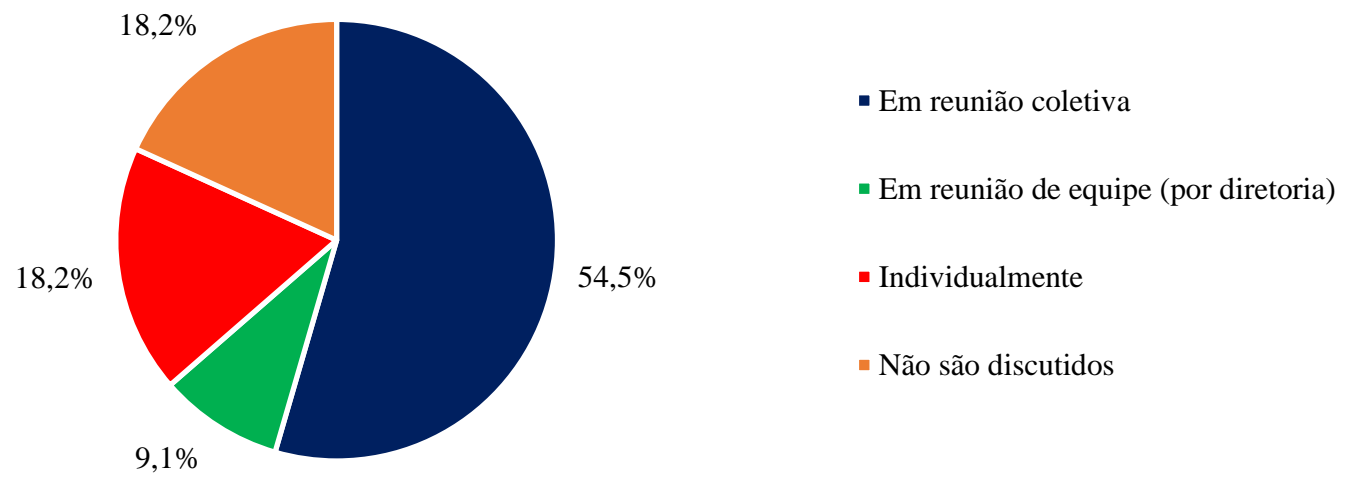

Fonte: Dados da Pesquisa (2020)

Nesse caso, compreende-se que os feedbacks dos resultados obtidos na avaliação precisam ser expostos e repassados para os demais membros da equipe. Independente do 
processo utilizado, é necessário que os resultados sejam apresentados e discutidos, a fim de contribuir com a melhoria das ações e tomada de decisões dessas entidades.

Por fim, foi questionada a opinião dos entrevistados em relação à principal contribuição da avaliação de desempenho para cada CA. As respostas obtidas estão destacadas no quadro 2.

Quadro 2 - Opinião dos entrevistados sobre a principal contribuição da avaliação de desempenho para o Centro Acadêmico

A avaliação é extremamente útil, pois possibilita realizar um diagnóstico e encontrar pontos de melhorias na gestão.

A avaliação de desempenho permite visualizar o todo, bem como especificar os pontos fortes e a melhorar.

Identificar as dificuldades em conciliar a participação em Centro Acadêmico, estágio/trabalho, vida acadêmica e pessoal. Dessa forma podemos encontrar a melhor maneira de conciliar tudo isso com cada membro da gestão e designar as tarefas de acordo com suas limitações e possibilidades.

Os feedbacks são sempre muito importantes enquanto a avaliação do desempenho de todas as diretorias e para a observação de um contexto geral.

Agregação de boas relações e trabalho em conjunto.

Para sabermos o que precisa ser melhorado e o que está dando certo, para assim evoluímos e contribuímos ainda mais de maneira positiva para nosso curso.

Melhoria interpessoal para membros do Centro Acadêmico.

Correção/aperfeiçoamento e manutenção de atividades e procedimentos.

Fonte: Dados da pesquisa (2020).

Através do Quadro 2, pode-se perceber que os participantes desta pesquisa apresentam opiniões relevantes no que diz respeito à importância que o Centro Acadêmico pode proporcionar em termos de contribuição para a comunidade acadêmica e na esfera profissional também, visto que, por meio desse grupo, muitas parcerias profissionais têm a possibilidade de acontecer.

Estudo de Maria et al. (2017) realizado com estudantes da Universidade Federal do Ceará destacaram o papel do CA no exercício da cidadania na $\square$ Instituição e relatam que, no geral, estão satisfeitos com a gestão e apontam como pontos fortes os serviços de divulgação institucional por e-mail e facebook e a promoção de eventos. Além disso, reforçam necessidade realizar avaliações que possibilitem tomar decisões assertivas e construir os processos de melhoria contínua.

Revista Expectativa, Toledo/PR, v.20, n. 3, p. 46-70, jul./set., 2021. 
A pesquisa de Gonçalves et al. (2015) ressaltam o papel relevante dos CA para formação complementar dos estudantes. A pesquisa aponta a necessidade de buscar meios para auxiliar e aprimorara a gestão, proporcionando melhorias para os discentes.

Maria et al. (2017) reforçam a contribuição dos CAs exercem no âmbito universitário, bem com a necessidade realizar avaliações que possibilitem tomar decisões assertivas e construir os processos de melhoria contínua.

\section{CONSIDERAÇÕES FINAIS}

O referido trabalho buscou analisar os Centros Acadêmicos enquanto uma organização em que indivíduos colaboram para atingir objetivos em comum, sobretudo os CAs dos cursos de Secretariado. Os CAs são entidades representativas, consideradas organizações do terceiro setor, portanto necessitam de uma gestão estruturada e sistêmica. Desta maneira, a abordagem dessa pesquisa apresenta-se bastante pertinente, uma vez que esses grupos trabalham para alcançar objetivos e necessitam de conhecimentos voltados para a gestão organizacional, compreendendo como se dá o processo de gestão e a avaliação de desempenho das equipes.

A avaliação de desempenho no âmbito dessas organizações se mostra relevante, uma vez que funciona como um instrumento de acompanhamento e controle das atividades desenvolvidas, a fim de adotar ações corretivas e de melhorias nas atividades administrativas.

Em suma, é pertinente considerar que os objetivos pretendidos foram alcançados, sendo possível observar a percepção dos respondentes, sobre a importância dos CAs, em termos de desenvolvimento do curso. Foi possível constatar que alguns CAs realizam algum tipo de avaliação interna com os seus membros, mesmo sem conhecer os procedimentos técnicos e teóricos que possam contribuir com esse processo. O indicador mais utilizado é o de produtividade, se enquadrando na esfera qualitativa, devido ao caráter administrativo dessa organização, atrelado aos objetivos que as equipes visam alcançar. De acordo com as respostas obtidas, observou-se que esse processo avaliativo vem trazendo resultados significativos para os CAs, sobretudo no melhoramento da gestão, e até mesmo das relações interpessoais, de acordo com os resultados interpretados, contribuindo para uma relação sinérgica.

Ressalta-se ainda que avaliação de desempenho proporciona desenvolver uma gestão

Revista Expectativa, Toledo/PR, v.20, n. 3, p. 46-70, jul./set., 2021. 
estratégica e dinâmica por meio de indicadores contribui com benefícios concretos e mensuráveis para toda a gestão, permitindo tomar decisões assertivas.

Por fim, acredita-se que a abordagem aqui apresentada, contribuirá para outras pesquisas científicas não somente para a área de Secretariado Executivo, mas também para qualquer curso superior que conte com centro ou diretório acadêmico, visto que não se têm atualmente um aparato teórico amplo sobre a perspectiva abordada neste artigo, tampouco análises empíricas que investiguem esse tipo de entidade estudantil.

\section{REFERÊNCIAS}

ARANHA, G. T. C; LEICHSENRING, M. L.; FOLEGATTI, J. C. Adaptação de um modelo de relatório gerencial para avaliação de serviços hospitalares. Serviço Social \& Saúde, Campinas, v. 2, n. 2, p. 83-102, 2015.

BISCOLI, F. R. V; CIELO, I. D. Gestão Organizacional e o Papel do Secretário Executivo. Revista Expectativa, v. 3, n. 1, 2004.

BRAGA, A. A.; OLIVEIRA, C. M.; SIENA, T. M. Fatores e aspectos que impactam o trabalho em equipe. Revista de Administração e Negócios da Amazônia, v. 3, n. 3, p. 5065, set./dez. 2011.

BRASIL. Lei $\mathbf{n}^{\mathbf{0}} \mathbf{6 . 5 5 6}$, de 5 de setembro de 1978. 1978. Dispõe sobre as atividades de secretário e dá outras providências. Disponível em:

http://www.planalto.gov.br/ccivil_03/leis/1970-1979/L6556.htm. Acesso em: 10 abr. 2020.

BRASIL. Lei no 7.377, de 30 de setembro de 1985. 1985. Dispõe sobre o exercício da profissão de secretário e dá outras providências. Disponível em:

http://www.planalto.gov.br/ccivil_03/Leis/L7377consol.htm. Acesso em: 11 abr. 2020.

BRASIL. Lei $\mathbf{n}^{\mathbf{0}} \mathbf{7 . 3 9 5}$, de 31 de outubro de 1985. 1985. Dispõe sobre os órgãos de representação dos estudantes de nível superior e dá outras providências. Disponível em: http://www.planalto.gov.br/ccivil_03/leis/L7395.htm. Acesso em: 13 abr. 2020.

BRASIL. Ministério da Educação. Conselho Nacional de Educação. Câmara de Educação Superior. Resolução no 3, de 23 de junho de 2005. Institui as Diretrizes Curriculares Nacionais para o curso de graduação em Secretariado Executivo e dá outras providências. Diário Oficial [da] República Federativa do Brasil, Poder Executivo, Brasília, DF, 27 jun. 2005. Seção 1, p.79.

CARVALHO, A. P. P. A Integração das novas mídias sociais à comunicação interna das organizações. 2015. 86f. Monografia (MBA em Marketing) - Universidade Federal Paraná, UFPR, Curitiba, 2015. 
CRESWELL, J. W. W. Projeto de pesquisa: métodos qualitativo, quantitativo e misto. 2. ed. Porto Alegre: Bookman, 2010.

DAFT, R. L. Organizações: teoria e projetos. 11. ed. São Paulo: Cengange Learning, 2014.

FENASSEC - Federação Nacional de Secretárias e Secretários. Conheça o histórico da profissão de secretariado: das associações civis à organização sindical e as leis da profissão. Revista Excelência, Recife-PE, v. 6, n. 19, ed. esp., p. 7, 2008.

FONSECA, J. C. et al. Gestão e um diretório acadêmico: um olhar sobre as organizações do movimento estudantil a partir da psicologia do trabalho e das organizações. Revista da graduação em Psicologia da PUC, Minas Gerais, v. 3, n. 5, jan./jun., 2018.

FRANÇA, R. D. Sistemas de controle no terceiro setor: um estudo exploratório das igrejas batistas da grande João Pessoa-PB. Dissertação (Mestrado em Ciências Contábeis) Programa de Pós-Graduação Multi-Institucional e Inter-regional em Ciências Contábeis da UNB/ UFPB/ UFPE/ UFRN, João Pessoa, 2007.

FRANCO, J. H. S.; SANTOS, J. N. Um estudo da relação entre o trabalho em equipe e a aprendizagem organizacional. GES - Revista Gestão e Sociedade, CEPEAD/UFMG. v. 4, n. 9, set./dez. 2010.

GIL, A. C. Como elaborar projetos de pesquisa. 4. ed. São Paulo: Atlas, 2002.

GIL, A. C. Métodos e técnicas de pesquisa social. 5. ed. São Paulo: Atlas, 1999.

GUIMARÃES, T. A.; NADER, R. M.; RAMAGEM, S. P. Avaliação de desempenho de pessoal: uma metodologia integrada ao planejamento e à avaliação organizacionais. RAP, Rio de Janeiro, p. 43-61, nov./dez. 1998.

KATZENBACH, J.; SMITH, D. La sabiduría de los equipos/ Team wisdom. México: CECSA, 1994.

MARIA et al. O Papel do Centro Acadêmico na Formação Cidadã do Universitário: um estudo de caso dos usuários do CABIRG/UFC. Revista de Biblioteconomia e Ciências da Informação, v.3, n. 1, p. 5-15, jan./jun., 2017.

MARIN, V. et al. A influência das atividades realizadas por um centro acadêmico em uma formação completa em engenharia. In: CONGRESSO BRASILEIRO DE EDUCAÇÃO EM ENGENHARIA - COBENGE, 39., 2011, Blumenau. Anais [...] Blumenau, 2011, out., p. 110.

MAXIMIANO, A. C. M. Introdução à administração. 8. ed. rev. e ampl. São Paulo: Atlas, 2011.

MORAES, L. A; BERNARDINI, P. Avaliação de Desempenho Como Ferramenta Gerencial em Empresas de Ourinhos e Região. Revista Hórus, v.11, n. 1, p. 42-56, 2016. 
MORIOKA, S. N. et al. Discutindo sustentabilidade no contexto de negócios e em relatórios de desempenho: análise de estudos de casos brasileiros. Revista Gest. Prod., São Carlos, v. 24, n. 3, p. 514-525, 2017.

MUNARETTO, L. F.; CORRÊA, H. L. Indicadores de desempenho organizacional: uso e finalidades nas cooperativas de eletrificação do Brasil. Revista Contabilidade Vista e Revista, Belo Horizonte, v. 27, n. 1, p. 25-41, jan./abr. 2016.

NEIVA, E. G.; D`ELIA, M. E. S. As novas competências do profissional de secretariado. 2. ed. São Paulo: IOB, 2009.

NONATO JÚNIOR, R. Epistemologia e teoria do conhecimento em secretariado executivo: a fundação das ciências da assessoria. Fortaleza: Expressão Gráfica, 2009.

PAGLIUSO, A. T; CARDOSO, R; SPIEGEL, T. Gestão organizacional: o desafio da construção do modelo de gestão. São Paulo: Saraiva, 2010.

ROCK CONTENT. Instagram: Saiba tudo sobre essa rede social. [2016-2018]. Disponível em: https://marketingdeconteudo.com/instagram/. Acesso em: 27 de jul. de 2020.

ROMAN, D. et al. Um estudo sobre a importância da administração estratégica como vantagem competitiva para as organizações. ReFAE - Revista da Faculdade de Economia, v. 8, n. 1, p. 40-52, 2017.

SCHULTZ, G. Introdução à gestão de organizações. Porto Alegre: Editora da UFRGS, 2016.

SOUSA, M. Q. L.; CAMPOS, A. C. S. F.; RAMOS, R. E. B. Trabalho em equipe: a base da qualidade nas organizações. In: Congresso Brasileiro de Educação em Engenharia COBENGE, 29., 2001. Anais [...]. Rio Grande do Sul: PUCRS, 2001, p. 8-14.

STAROSKY FILHO, L. As mudanças que o marco regulatório trouxe para as organizações alternativas. Revista Gestão e Secretariado (GeSec), São Paulo, v.11, n. 1, jan. /abr., p. 2040, 2020.

VARGAS, S. B. et al. Indicadores não-financeiros de avaliação de desempenho: análise de conteúdo em relatórios de administração de empresas e telecomunicações. Sociedade,

Contabilidade e Gestão, Rio de Janeiro, v. 11, n.1, jan./abr. 2016.

VERGARA, S. C. Gestão de pessoas. 8. ed. São Paulo: Atlas, 2009. 